\title{
BJSM
}

\section{Popular drugs in sport: descriptive analysis of the enquiries made via the Drug Information Database (DID)}

A Petróczi and D P Naughton

Br J Sports Med 2009 43: 811-817 originally published online November 3, 2008

doi: 10.1136/bjsm.2008.052894

Updated information and services can be found at:

http://bjsm.bmj.com/content/43/11/811.full.html

Topic collections Articles on similar topics can be found in the following collections

Drugs: musculoskeletal and joint diseases (8151 articles)

Notes

To order reprints of this article go to:

http://bjsm.bmj.com/cgi/reprintform

To subscribe to British Journal of Sports Medicine go to:

http://bjsm.bmj.com/subscriptions 


\title{
Popular drugs in sport: descriptive analysis of the enquiries made via the Drug Information Database (DID)
}

\author{
A Petróczi, D P Naughton
}

School of Life Sciences, Kingston University, Kingston upon Thames, London, UK

Correspondence to: Dr Petróczi, Kingston University, School of Life Sciences, Kingston University, Penrhyn Road, Kingston upon Thames, London KT1 2EE, UK;

A.Petroczi@kingston.ac.uk

Accepted 2 October 2008 Published Online First

3 November 2008

\begin{abstract}
Objective: To analyse enquiries made in the Drug Information Database (DID) to develop a better understanding of athletes' interests and concerns regarding the prohibited status of available substances.
\end{abstract}

Setting: Retrospective analyses of anonymous enquiries recorded in the DID in 2006 and 2007.

Participants: Athletes and supporting personnel.

Results: The DID recorded 223717 enquiries with 200 of the $>6000$ UK licensed pharmaceutical products receiving over 100 enquiries each. The majority (79.2\%) of these enquiries were in the pharmaceutical product category, followed by recreational drugs $(10.4 \%)$. A variety of common medications were subject to enquiry, with anti-inflammatory agents, decongestants and bronchodilators being most common; a trend in keeping with reported medication use by athletes. Of all enquiries, $42 \%$ were not found owing to misspelled words or enquiries about unregulated substances. The proportion of enquiries about substances not listed in the database is relatively high and has increased over the 24 month observation period.

Conclusion: The DID is a well-used information resource with some 10000 enquiries being made each month. Of the c. $60 \%$ of successful enquiries, the major focus was on pharmaceutical products. With some $73 \%$ of enquiries being made by the athletes themselves, further investigations are warranted to explore enquiry patterns in relation to specific sports. Of the unsuccessful enquiries, a large number were related to nutritional supplements, which warrants further investigation. The DID database appears to be a valid mirror of athletes' chemically assisted practices and may be successfully used to inform health professionals as well as antidoping prevention programmes.

The widespread use of chemically assisted performance enhancements in sport is a growing concern, with the emphasis on the need for harm reduction policies and intervention, underpinned by empirical evidence from clinical trials. ${ }^{1}$ Considerable advances have been, and continue to be, made in the development and application of the analytical sciences that underlie the detection of prohibited performance-enhancing substances (PES) both in and out of competition. In addition to advances in chemical testing, ${ }^{2}$ the widespread adoption of the World Anti-Doping Agency (WADA) code and harmonisation of testing and international standards have facilitated the recent gains in "policing" drug use in sports to a large degree. ${ }^{3}$ The International Olympic Committee (IOC)-sanctioned empirical testing of biofluids (urine and blood) is being extended by the exploratory analyses of hair samples, which are recognised in forensic testing and toxicology but are not accepted as sole evidence for a doping offence. $^{4-8}$ Alternative approaches to reduce drug use in sports include education and studies designed to elucidate the reasons that underlie decisions to partake in drug use.

Practices of chemically assisted performance enhancements reach beyond using prohibited drugs and methods. Recent studies show that a noteworthy proportion of athletes take nutritional supplements daily ${ }^{9-12}$ and the majority of users of supplements in sports fail to take appropriate supplements to achieve their desired health-maintenance or performance-related outcomes. ${ }^{13-15}$ This mismatch between rationale underlying supplement use and the outcomes of the chosen supplements could form part of an educational programme to eradicate misplaced supplement use in sports. However, these literature reports may also be useful in designing new trials and testing programmes to evaluate the side effects of supplements. In addition to supplements, athletes competing at international sport events reported an alarmingly high use of a number and combination of nutritional supplements, over-the-counter (OTC) and prescription-only medications, ${ }^{11}{ }^{16-19}$ a pattern that is mirrored in sub-elite athlete populations. ${ }^{20}$ Among Belgian athletes, the reported use of OTC medication has increased from $19.8 \%$ to $24.7 \%$ in 3 years (2002-5), with the proportion of users above $35 \%$ in certain sports (such as corticosteroids in cycling). ${ }^{21}$

Whilst antidoping prevention programmes target high-performing athletes, the use of performance-enhancing substances has spread beyond elite sports ${ }^{22}$ and is reaching epidemic proportions. ${ }^{1}$ The complexities of ranges of prescription and over-the-counter medicines, social drugs and supplements, along with the broad range of products which contain them, necessitate an ever-watchful eye from athletes and coaching teams so that inadvertent doping does not occur. According to the strict liability principle of the WADA Code, the ultimate responsibility rests with the athlete and it is irrespective of intention. A clear, authoritative and accessible resource is required for athletes and their support team to discriminate between readily available drugs with varying prohibition status.

The risk to athletes is twofold: in addition to the scenario of inadvertently failing a doping test, several prescription and OTC medicines have known side effects that may hinder an athlete's performance. 
This concern is exemplified by the well-known gastric irritation caused by some non-steroidal anti-inflammatory drugs (NSAIDs). ${ }^{23}$ In a report by Berglund and Sundgot-Borgen, ${ }^{24}$ estimated use of NSAIDs is some six to tenfold higher in Olympic athletes than in the age-matched Swedish population. However, it is notable that, despite many estimates of higher use in athletes, only one study has compared NSAID use with that in age-matched controls. ${ }^{16}$ Given the paucity of rigorous studies on NSAID use by athletes, clearly a great deal of research is warranted to obtain a clear picture of prescription and OTC medicines use by athletes. A recent review by Alaranta et $a l^{17}$ draws upon numerous studies that relate higher prescription drug use by athletes whilst noting the potential detrimental side effects. These include antiasthmatic and antiallergic medicines, along with NSAIDs and oral antibacterials.

Owing to the enormous number and variety of supplements, prescription and OTC medicines available, along with a lack of clear information regarding doping, further research is required for information on which studies should be undertaken in terms of drug types in order to inform WADA testing and antidoping prevention programmes. One approach to this conundrum is to utilise the drug information databases to study patterns of athlete enquiries, assuming that enquiries are true reflections of interest and behaviour or behavioural intention. While enquiries do not necessarily equate to uses, it is reasonable to assume that athletes make enquiries about the prohibited status of the drugs or substances they are taking or considering for medical or performance-enhancing reasons.

In a similar fashion, studies of the trends, patterns and psychology that underpin drug use in sport may be useful for further consideration, investigation or policing both now and in the future. This approach may also be extended to potentially inform WADA guidelines by monitoring the number of users, substances and degrees of use that are made of drug information databases. Through the UK Sport website, a comprehensive Drug Information Database (DID) $)^{25}$ is available as a guide regarding the non-prohibited/prohibited status of UK licensed pharmaceuticals and OTC medicinal products in competitive sport. A number of resources are used to keep the database up to date, in line with the current WADA prohibited list, including the British National Formulary, ${ }^{26}$ Chemist and Druggist ${ }^{27}$ and Monthly Index of Medical Specialties. ${ }^{28}$ The DID is designed for support staff and athletes performing at or above a given standard in their sport, and is regularly updated each month and fully verified twice a year by professionally trained pharmacists with expertise in elite sport.

\section{Aims}

This report presents the analyses of patterns of use of the DID during 2006 and 2007, as a function of enquiries made in the following categories: i) user profile, ii) sport type, iii) frequency of enquiries per substance, iv) success rates in finding the substance of interest, v) class of substance, and vi) enquiries regarding substances outside the remit of the database (ie, unlisted substances). The primary aim of this report is to make the first step toward developing a detailed picture and a better understanding of interests and concerns of those involved in sport (athletes and their support networks) regarding the prohibited status of commercially available medicines, supplements and performance-enhancing substances.

\section{METHODS}

The underlying assumption of this study is that enquiries registered via the DID reflect the use or potential use of the
Table 1 Pattern of enquiries expressed as a function of enquirer

\begin{tabular}{|c|c|}
\hline Enquiry made by & $\begin{array}{l}\text { Number of enquiries (\% of the total enquiries } \\
\text { made) }\end{array}$ \\
\hline Athlete & $136519(73.1)$ \\
\hline Parent & $12620(5.6)$ \\
\hline Governing body official & $9615(4.3)$ \\
\hline Coach & 9907 (4.4) \\
\hline Other & 8599 (3.8) \\
\hline General practitioner & $8061(3.6)$ \\
\hline Student & $6258(2.8)$ \\
\hline Pharmacist & 4081 (1.8) \\
\hline Teacher & $1056(0.5)$ \\
\hline
\end{tabular}

queried substance, hence providing a valid picture of the most popular drugs and substances. The database is searchable anonymously but does provide a unique reference number for users to keep a record. ${ }^{29}$ The search can be made by brand name or individual ingredients. Demographic information collected along with the enquiry is limited to role (table 1) and sport (table 2), where users must select from the drop-down list in the response window. Country of purchase is also recorded. The system allows users to type partial information (a word fragment) into the search box and offers a detailed list of the searched word or fragment of the name to choose from. The result shows the prohibited status of the drug both in competition and out of competition, lists the main active ingredient and is provided with a reference number and the time and date when the enquiry was made (fig 1). As the research utilised a data set recorded anonymously and there was no contact with participants, it was exempt from ethical review.

The timeframe of this investigation encompasses 24 months between 1 January 2006 and 31 December 2007. With the exception of the Olympic Games, the 24 month period is suitably long to capture major sport events, including the leadup time to, and preparation for, the event. Data from the DID database were downloaded and transferred into Excel worksheets, where "found" and "not found" (ie, unlisted substances) data were kept separately. The smallest time-unit selected for

Table 2 Pattern of enquiries expressed by type of sport

\begin{tabular}{lc}
\hline Sport & Number of enquiries (\% of the total enquiries made) \\
\hline Athletics & $24137(10.79)$ \\
All sports & $20356(9.10)$ \\
Rugby Union & $16254(7.27)$ \\
Swimming & $15772(7.05)$ \\
Cycling & $9693(4.33)$ \\
Ice hockey & $7743(3.46)$ \\
Football (FA) & $7558(3.38)$ \\
Cricket & $5808(2.60)$ \\
Gymnastics & $5632(2.52)$ \\
Rugby League & $5338(2.39)$ \\
Equestrian & $4998(2.23)$ \\
American football & $4798(2.14)$ \\
Shooting & $4755(2.13)$ \\
Rowing & $4418(1.97)$ \\
Basketball & $4028(1.80)$ \\
Hockey & $3703(1.66)$ \\
Archery & $3654(1.63)$ \\
Volleyball & $3653(1.63)$ \\
Canoeing & $3428(1.53)$ \\
Judo & $2972(1.33)$ \\
Total of the above sports & $158698(70.94)$ \\
\hline
\end{tabular}




\begin{tabular}{|c|c|c|c|}
\hline \multicolumn{4}{|l|}{ Search results } \\
\hline $\begin{array}{l}\text { You have searched for: } \\
\text { DIN: } \\
\text { Route of administration: } \\
\text { Nationality: } \\
\text { Sport: } \\
\text { Nation of purchase: }\end{array}$ & \multicolumn{3}{|c|}{$\begin{array}{l}\text { Tylenol extra strength gelcaps tab } 500 \mathrm{MG} \\
00863270 \\
\text { Not applicable } \\
\text { United Kingdom } \\
\text { All sports } \\
\text { Canada }\end{array}$} \\
\hline Ingredients & In con & etition & Out of competition \\
\hline Acetaminophen & Not $\mathrm{p}$ & ibited & Not prohibited \\
\hline Overall & Not $\mathrm{p}$ & ibited & Not prohibited \\
\hline \multicolumn{4}{|c|}{$\begin{array}{l}\text { Reminder: you must check that the ingredients and route of administration listed here match those on the } \\
\text { product being queried. Please ensure you read the WADA regulations for more information regarding } \\
\text { your enquiry. }\end{array}$} \\
\hline \multicolumn{4}{|c|}{ NB. Intravenous infusions are prohibited, except as a legitimate medical treatment. } \\
\hline \multicolumn{4}{|c|}{ You should record your reference number: 413635} \\
\hline \multicolumn{4}{|c|}{ WADA regulations click here to show details } \\
\hline \multicolumn{4}{|c|}{$\begin{array}{l}\text { Possible outcomes } \\
\text { This page provides the status of a particular drug on the world anti-doping agency's } \\
\text { prohibited list. Possible outcomes are: }\end{array}$} \\
\hline Not prohibited & Prohibited & \multicolumn{2}{|c|}{ Prohibited-particular sports } \\
\hline \multicolumn{4}{|c|}{$\begin{array}{l}\text { Therapeutic use exemptions } \\
\text { For any substance that is prohibited in sport, a therapeutic use exemption (TUE) may be } \\
\text { granted for a medically justified reason. For information on applying for a standard TUE } \\
\text { or a abbreviated TUE, see this page....More }>>\end{array}$} \\
\hline \multicolumn{4}{|l|}{$\begin{array}{l}\text { Feedback } \\
\text { Has this fulfilled your } \\
\text { enquiry? }\end{array}$} \\
\hline
\end{tabular}

\begin{tabular}{|c|c|c|c|}
\hline \multicolumn{4}{|l|}{ Search results } \\
\hline \multicolumn{4}{|c|}{$\begin{array}{ll}\text { You have searched for: } & \text { Nandrolone decanoate } \\
\text { Route of administration: } & \text { Not applicable } \\
\text { Nationality: } & \text { United Kingdom } \\
\text { Sport: } & \text { All sports } \\
\text { Nation of purchase: } & \text { United Kingdom }\end{array}$} \\
\hline \multirow{2}{*}{\multicolumn{2}{|c|}{$\begin{array}{l}\text { Ingredients } \\
\text { Nandrolone decanoate }\end{array}$}} & In competition & Out of competition \\
\hline & & Prohibited & Prohibited \\
\hline \multicolumn{2}{|l|}{$\begin{array}{l}\text { Nandrolone decanoate } \\
\text { Overall }\end{array}$} & Prohibited & Prohibited \\
\hline \multicolumn{4}{|c|}{$\begin{array}{l}\text { Reminder: you must check that the ingredients and route of administration listed here match those on the } \\
\text { product being queried. Please ensure you read the WADA regulations for more information regarding } \\
\text { your enquiry. }\end{array}$} \\
\hline \multicolumn{4}{|c|}{ NB. Intravenous infusions are prohibited, except as a legitimate medical treatment. } \\
\hline \multicolumn{4}{|c|}{$\begin{array}{l}\text { You should record your reference number: } 413637 \\
\text { Sun, } 10 \text { Feb } 2008 \text { 08:29:22 + 0000 }\end{array}$} \\
\hline \multicolumn{4}{|c|}{ WADA regulations click here to show details } \\
\hline \multicolumn{4}{|c|}{$\begin{array}{l}\text { Possible outcomes } \\
\text { This page provides the status of a particular drug on the world anti-doping agency's } \\
\text { prohibited list. Possible outcomes are: }\end{array}$} \\
\hline Not prohibited & & Prohibited-parti & sports \\
\hline \multicolumn{4}{|c|}{$\begin{array}{l}\text { Therapeutic use exemptions } \\
\text { For any substance that is prohibited in sport, a therapeutic use exemption (TUE) may be } \\
\text { granted for a medically justified reason. For information on applying for a standard TUE or } \\
\text { a abbreviated TUE, see this page...More }>>\end{array}$} \\
\hline $\begin{array}{l}\text { Feedback } \\
\text { Has this fulfilled your } \\
\text { enquiry? }\end{array}$ & & No & \\
\hline
\end{tabular}

Search results

You have searched for: Nationality:

Nation of purchase:

Overal

\section{Nandrolone decanoate United Kingdom All sports United Kingdom}

Prohibited

Figure 1 Search results for a non-prohibited (Tylenol) and a prohibited (Nandrolone) substance from the DID database.

this study was 1 month, but the DID system allows analyses for each day of any given period. Substances in the "found" database were categorised by their main effect and whether they were pharmaceutical drugs, nutritional supplements, recreational drugs, herbal products or other. Unlisted substances were categorised by their effect and checked against the WADA Prohibited List 2006 and 2007. ${ }^{3031}$ Statistical analyses were conducted using Excel XP version and SPSS version 15.0.

\section{RESULTS AND DISCUSSION}

A total of 223717 enquiries were made to the UK DID between 1 January 2006 and 31 December 2007. The number of enquiries made each month varies considerably from 6558 to 12 480, with a monthly average of 9322 (SD 1483). Ignoring the sequence, the distribution of the monthly enquiries followed the normal distribution curve (Kolmogorov-Smirnov $Z=0.503, p=0.962$, where $\mathrm{H}_{0}$ : normality assumed).

During the 24 month period of this investigation, enquiries were made predominantly by athletes $(73.1 \%)$, with parents, governing body officials, teachers and coaches accounting for a total of $14.8 \%$ of enquiries. Healthcare professionals (GPs and pharmacists) and students made $5.4 \%$ and $2.8 \%$ of the enquiries, respectively (table 1).

In contrast to the heterogeneous pattern observed when classified by enquirer, the pattern observed for type of sport gives a much more even spread (table 2). Enquirers classified themselves as track and field athletes in $10.79 \%$ of cases, with "all sports", rugby union and swimming scoring 9.10\%, 7.27\% and $7.05 \%$ respectively. After cycling, with $4.33 \%$ of enquiries, eight sports fell into the range between $2 \%$ and $3.5 \%$, showing a good spread throughout sporting types. In all, 20 categories accounted for some $70 \%$ of all enquiries, athletics being the only sport with over $10 \%$.

While the number of enquiries made each month remained within 1 standard deviation of the mean, there were two low and two high peaks over the 24 month period (fig 2). The months in which the numbers of enquiries made were below 1
SD of the mean were the Decembers of 2006 and 2007. The two noticeable peaks (both above mean $+2 \mathrm{SD}$ ) occurred in October 2006 and July 2007.

The pattern of enquiries for the two peaks (October 2006 and July 2007) and for the two low winter months (December 2006 and 2007) did not diverge considerably from the overall pattern, except for October 2006. In this month, only $62 \%$ of the enquiries were made by athletes, whereas pharmacists contributed an increased proportion (12.7\%) of the total enquiries made during October 2006, a phenomenon which warrants further investigation. During the other peak, athletes' contribution to the number of enquiries in July 2007 was slightly higher $(82 \%)$ than the overall mean of $73.1 \%$, but no decrease stood out among the other groups.

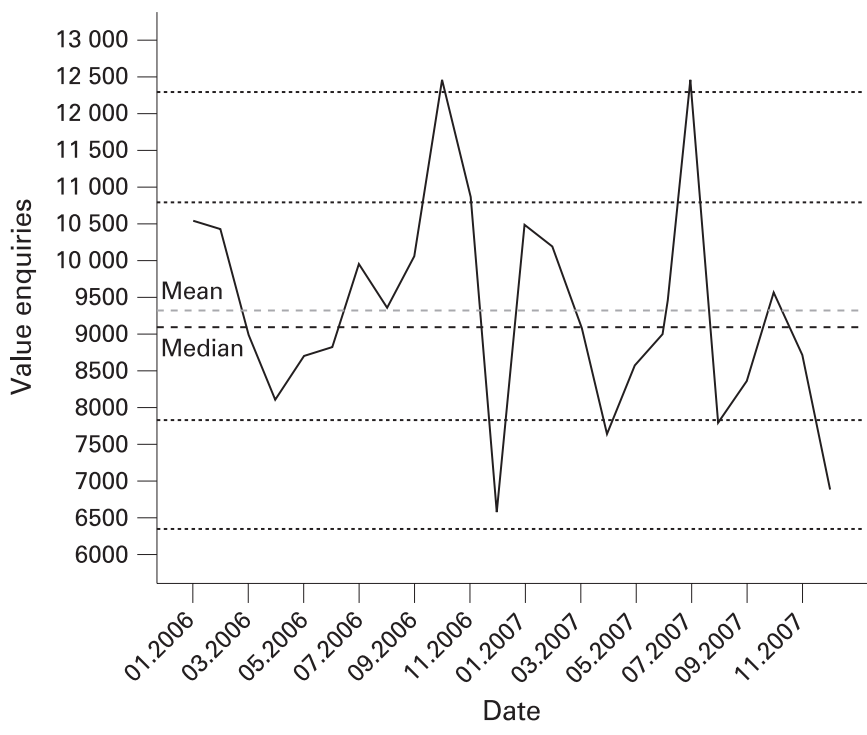

Figure 2 Trend in the number of enquiries made between January 2006 and December 2007 via the Drug Information Database (DID). 


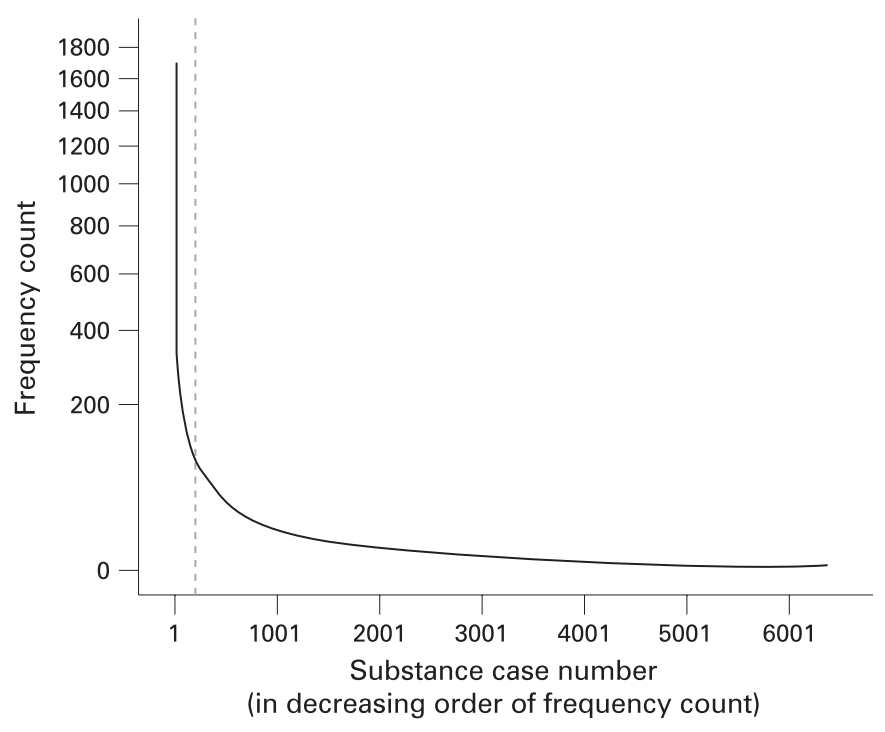

Figure 3 Number of enquiries per substance with frequency (y axis) and substance type ( $\mathrm{x}$ axis).

Detailed analyses did not provide any specific explanation for the two "low frequency" months, but they revealed interesting reasons for the two peaks. Enquiries made by pharmacists in October 2006 alone contributed 33.9\% to the total number of enquiries made over the 24 month period. The remaining $66.1 \%$ were comparatively evenly distributed between the remaining 23 months, with a mean of $2.9 \quad(1.1) \% \quad(\min =1.2 \%$, $\max =5.6 \%$ ). As the numbers of enquiries made by other user groups remained close to the monthly average, it can be concluded that the noticeable increase in October 2006 was owing to the elevated number of enquiries made by pharmacists. In contrast to the monthly average of 170 enquiries (130 if October 2006 is excluded), pharmacists registered 1094 enquiries in October 2006. Fifty-eight percent of the drugs in which pharmacists showed an interest were found in the DID database, with no specific pattern of substances in either data set.

The analysis of the other "peak", July 2007, provided a very peculiar picture. The increased number of enquiries (8088) during this month was owing to one particular type of sport: "equestrian" (including paralympic equestrian). There was over a 50 -fold increase in the number of enquiries from those who registered as "equestrian" (3159 vs 61, excluding July 2007 from the mean). July 2007 alone contributed $69 \%$ of all enquiries from the equestrian sport in the observed 24 month period, which warrants further exploration. The number of enquiries made during each of the remaining 23 months did not diverge considerably from the mean and remained under 100 per month. Almost all of the total 3159 enquiries were registered as made by athletes $(3143 ; 99.5 \%)$. A similar pattern was found among enquiries made by paralympic equestrian athletes. Of the total 609 enquiries over the 24 month period, 516 enquiries (85\%) were registered at the DID website in July 2007, all exclusively from athletes. Apart from the preceding month with 35 enquiries (5.7\%), 28 from athletes, the number of enquiries made was $\leqslant 10$ in each month. Slightly over half (1696) of the drugs equestrian athletes were interested in were found in the DID, but without a particular pattern. The highest hit on the licensed list was with 10 logged enquiries about sodium bicarbonate, followed by mannitol (eight) and glycerol trinitrate (six). Among the unlisted substances, dextrose was on the top of the list with 15 enquiries, followed by cromoglycate (eight) and sodium (seven).

Analyses of all the compounds for which enquiries were made at the DID site demonstrated that an exponential curve exists, with some 200 substances receiving more than 100 enquiries each (fig 3). The horizontal line in fig 3 represents the cut off point after the first 200 substances, ordered in decreasing order of frequency. In order to make the exponential curve more readable, normalising power transformation with $e^{(-0.5 x)}$ exponent was used. Clearly, with enquiries for over 6000 substances, there were a large number receiving a low number of enquiries.

The top 200 substances for which the highest numbers of enquiries were received were categorised as i) pharmaceutical products, ii) recreational drugs, iii) supplements or iv) herbal products. These 200 substances constitute $20.3 \%$ of all enquiries made, and each received between approximately 1700 and 100 enquiries. The majority (79.2\%) of the enquiries made were in the pharmaceutical product category, followed by recreational drugs $(10.4 \%)$, herbal products $(4.2 \%)$ and nutritional supplements $(1.8 \%)$, whereas $4.3 \%$ of the first 200 substances were categorised as "other" and were typically excipients in a formulation. In the pharmaceutical product category, the highest number of enquiries was made regarding substances that are included in common medications, such as NSAIDs, decongestants and bronchodilators (table 3).

Specifically, the most frequent enquiries were on variants of salbutamol (1882), caffeine (1702) and ingredients of pain/fever relievers (ibuprofen and paracetamol, 1412 and 1349, respectively) and cold medications (ephedrine, 1151). Both ephedrine and salbutamol are bronchodilators and their in-competition use is prohibited. However, salbutamol may be used under the therapeutic use exemption (TUE) scheme. For the pattern of reporting expressed by active agents and other medications see table 4. The high frequency of enquiries about NSAIDs and bronchodilators is in keeping with the literature precedents. ${ }^{17}$

One possible explanation for the relatively high prevalence of decongestants and asthma medications among the enquiries is the exercise-induced asthma that has been documented among winter endurance athletes. ${ }^{32}{ }^{33}$ It is equally possible that these substances have performance-enhancing effects but are allowed if prescribed with evidence of medical need under the TUE scheme. Therefore, further investigation is warranted into sport-specific enquiries about potentially performance-enhancing substances (ie, salbutamol, corticosteroids, etc).

The diversity of substances is reflected in the high number of enquiries that were unsuccessful (ie, substances that were "not found") which was $42 \%$. The ratio of "found" to "not found" substances, which was calculated by dividing the number of substances found by the number of enquiries unlisted in the

Table 3 Pattern of reporting expressed by class of active agent

\begin{tabular}{lll}
\hline Substance type & Group & $\begin{array}{l}\text { Frequency count (\% of } \\
\text { the top 200 enquiries) }\end{array}$ \\
\hline Local constituent & NSAID & $5929(13.06)$ \\
Local constituent & Corticosteroid & $5051(11.13)$ \\
Brand & Multiple & $4019(8.86)$ \\
Brand & Decongestant & $3511(7.74)$ \\
Brand & Bronchodilator & $3035(6.69)$ \\
Local constituent & Stimulant & $2842(6.26)$ \\
Local constituent & Antihistamine & $2554(5.63)$ \\
Local constituent & Stimulant (bronchodilator) & $1474(3.25)$ \\
Local constituent & Antibiotic & $1196(2.64)$ \\
\hline
\end{tabular}


Table 4 Pattern of reporting expressed by active agent

\begin{tabular}{llllll}
\hline Substance & $\begin{array}{l}\text { In-competition } \\
\text { Status }\end{array}$ & $\begin{array}{l}\text { Out of competition } \\
\text { Status }\end{array}$ & $\begin{array}{l}\text { Number of } \\
\text { enquiries }\end{array}$ & $\begin{array}{l}\text { \% of the first } \\
\mathbf{2 0 0} \text { enquiries } \\
\text { (45 381) }\end{array}$ & $\begin{array}{l}\text { \% ofl } \\
\text { enquiries } \\
\text { (223 717) }\end{array}$ \\
\hline Salbutamol & Prohibited & Prohibited & 1882 & 4.2 & 0.84 \\
Caffeine & Not prohibited & Not prohibited & 1702 & 3.7 & 0.76 \\
Ibuprofen & Not prohibited & Not prohibited & 1412 & 3.1 & 0.64 \\
Paracetamol & Not prohibited & Not prohibited & 1349 & 3.0 & 0.60 \\
Ephedrine & Prohibited & Not prohibited & 1151 & 2.5 & 0.50 \\
Cetirizine hydrochloride & Not prohibited & Not prohibited & 767 & 1.7 & 0.34 \\
Loratadine & Not prohibited & Not prohibited & 709 & 1.6 & 0.32 \\
Prednisolone & Prohibited & Not prohibited & 697 & 1.5 & 0.31 \\
Cocaine & Prohibited & Not prohibited & 691 & 1.5 & 0.31 \\
$\begin{array}{l}\text { Pseudoephedrine } \\
\text { hydrochloride }\end{array}$ & Not prohibited & Not prohibited & 689 & 1.5 & 0.31 \\
Cannabis & & & & 1.5 & 0.29 \\
$\begin{array}{l}\text { Pseudoephedrine } \\
\text { Phenylephrine }\end{array}$ & Prohibited & Not prohibited & 671 & 1.4 & 0.29 \\
hydrochloride & Not prohibited & Not prohibited & 650 & 1.4 & 0.27 \\
Amoxicillin & & Not prohibited & 617 & & \\
\hline
\end{tabular}

DID, has been progressively decreasing since January 2006 (fig 4). The reasons for the presence of "not found" substances are twofold: i) misspelled words are not recognised by the system and are treated as a separate (not found) entry and ii) enquiries made with regard to nutritional supplements, herbs and other non-vitamin non-mineral substances are not under the remit of the British National Formulary, Chemist and Druggist and Monthly Index of Medical Specialties, ${ }^{26-28}$ and are hence not included in the database.

In the 2 year period of investigation, 93926 enquiries were not found in the database. From the list of substances unlisted in the DID, the 24 substances with a minimum of 100 enquiries were categorised (table 5). This level of frequency is consistent with the "found" data (fig 4). The most frequent "unlisted" enquiry was creatine (24.05\%), followed by various commercial products for muscle building (HMB, Maximuscle, Methoxyisoflavone) and some form of sugar (dextrose, glucosamine) at $9.20 \%$ and $7.88 \%$ respectively.
Substances enquired about but not found in the DID contain a mix of prohibited and non-regulated substances, with some clearly prohibited compounds (steroids, $\beta$-blockers and cannabis). The list also contains stimulants used in commercially available drinks (ie, taurine in Red Bull), and some natural products may be capable of causing positive doping results (ie, Tribulus terrestris). Commercial products for muscle building are also prone to deliberate contamination (spiking) with prohibited substances. ${ }^{34}$

\section{CONCLUSIONS}

In a survey among UK athletes, respondents believed that unintentional doping offences are mainly caused by inadequate labelling, changes in composition of supplements and lack of information, and felt that increased awareness of the UK Sport website and regularly updated list of acceptable supplements would help to prevent inadvertent doping. ${ }^{35}$
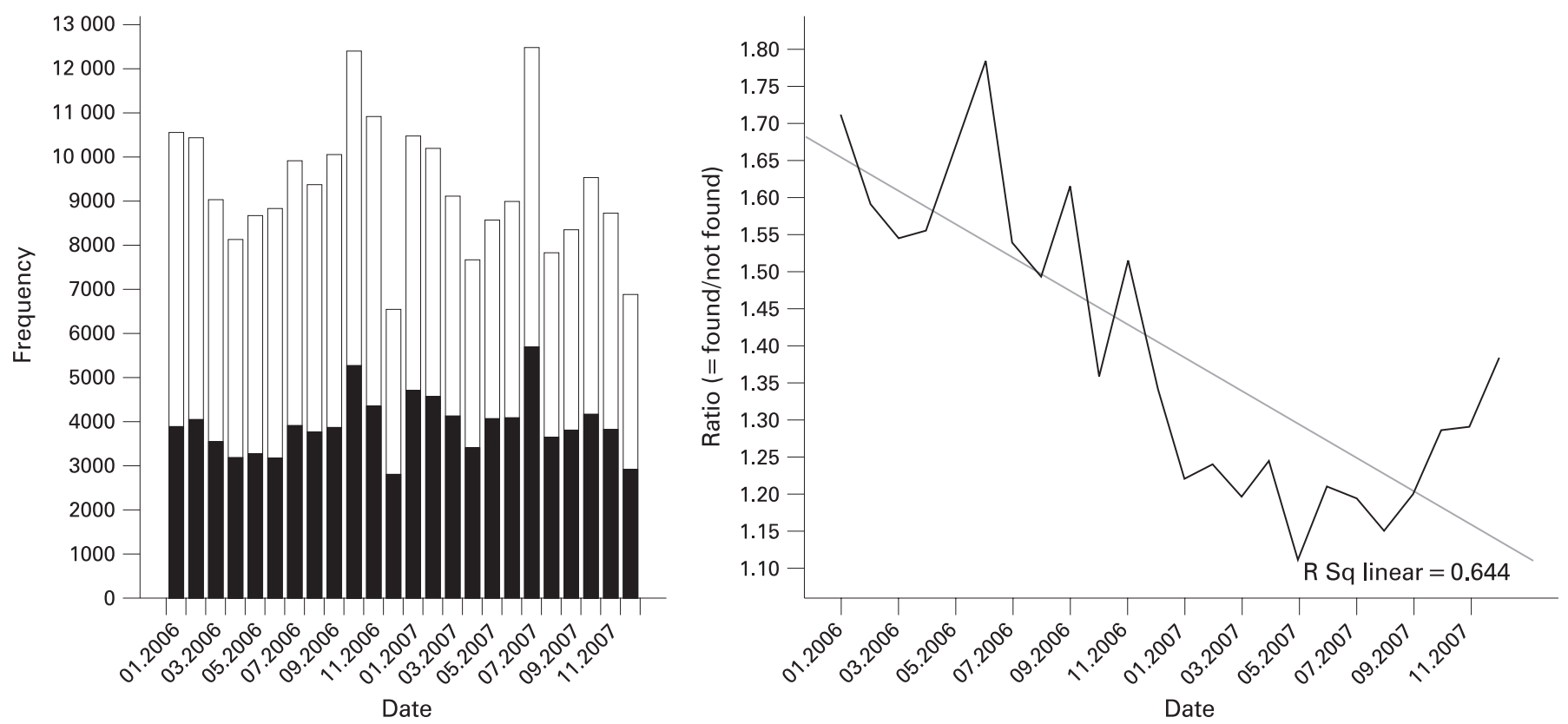

Figure 4 Trend in the ratio of found to not-found substances over 2 years (2006-7). 
Table 5 Pattern of enquiries not found and categorised as "unlisted"

\begin{tabular}{ll}
\hline Substance & $\begin{array}{l}\text { Number of enquiries (\% of the total } \\
\text { number of enquiries made up to 100 } \\
\text { per substance (8945)) }\end{array}$ \\
\hline Creatine & $2152(24.06)$ \\
Muscle builder & $823(9.20)$ \\
Sugar & $705(7.88)$ \\
Steroid & $679(7.59)$ \\
Taurine & $591(6.61)$ \\
Tribulus terrestris & $368(4.11)$ \\
Caffeine & $365(4.08)$ \\
Mineral retention (microcrystalline cellulose) & $308(3.44)$ \\
Painkiller/fever medication & $303(3.39)$ \\
Magnesium salt & $271(3.03)$ \\
Allergy medication & $277(3.10)$ \\
Protein & $259(2.90)$ \\
Guarana & $219(2.45)$ \\
Glutamine & $191(2.14)$ \\
Cold medication & $175(1.96)$ \\
Joint protection (glucosamine sulphate) & $171(1.91)$ \\
E211 (sodium benzoate) & $170(1.90)$ \\
Artificial sweetener (aspartame) & $165(1.84)$ \\
Beta-blocker & $149(1.67)$ \\
L-carnitine & $140(1.57)$ \\
Melatonin & $140(1.57)$ \\
Cannabis & $116(1.30)$ \\
L-glutamine & $107(1.20)$ \\
Dicalcium phosphate & $101(1.13)$ \\
\hline
\end{tabular}

The DID is highly used, with a healthy spread of users from a variety of sports, with some $75 \%$ of enquiries being made by the athletes themselves. It is important to note that the DID only covers the drugs that are sufficiently and robustly legislated to minimise the risk of contamination (e.g. medicines). Therefore supplements, herbal remedies and other non-herb non-mineral substances are not covered in the DID. A variety of common medications were enquired about, with anti-inflammatory agents, decongestants and bronchodilators being most common. As this finding is congruent with the self-reported use of OTC and prescription medicines, this finding supports the assumption that the DID data can be successfully used to learn about the key ingredients of athletes' medication and supplementation practices.

As there is growing concern about the use and potential misuse of OTC medication among athletes, developing a better understanding of drug use by athletes is crucially important for policy makers and health professionals alike for testing and advisory functions. The literature typically focuses on a single (major) sport event, and can therefore only give a snapshot of athletes' medication; this investigation adds useful information accumulated over 2 years. Results from this paper can also offer a unique contribution to the UK antidoping prevention programmes by providing information otherwise unavailable. The anonymity of the DID, coupled with the importance of providing correct information (ie, drug name, constituents, or sports), is likely to yield reliable information. Future research will aim to i) expand the timeframe of the investigation with specific attention to the months leading up to the multi-sport events (Olympic Games, Commonwealth Games, etc.), ii) expand the investigation to all substances enquired, iii) investigate OTC and prescribed medication use by sports and iv) research substances not found in the current DID.

Furthermore, the results of this paper highlight the need for an improved feedback mechanism when the substance is

\section{What is already known on this topic}

- There is growing concern about the use of over-the-counter (OTC) medication potentially leading to misuse by athletes.

- Literature precedents only give a snapshot of athletes' medication, typically based on self-reports at single sport events.

- Epidemiological profiles of OTC medication and supplement use by athletes are largely unknown.

\section{What this study adds}

- There is a major demand for information accessible on the DID among athletes.

- The major focus of successful enquiries was on products from the pharmaceutical industry (c. $80 \%$ ), with some $10 \%$ being on recreational drugs.

- Approximately $40 \%$ of enquiries were not matched owing to typing errors or relating to substances beyond the remit of the database.

- The DID database appears to be a valid mirror of athletes' medication and supplementation practices, and may be successfully used to inform antidoping prevention programmes.

non-recognised. Improvement can include information on assessing the risk of supplements, warning about potential contamination (especially if the substance is purchased from an unregulated source) and a link to the UK Sport position statement regarding supplements.

Acknowledgements: The authors thank UK Sport, especially Joe Marshall for his useful comments and help, and Jerry Bingham and Allison Holloway, for their support for this project.

Caveat: Conclusions and recommendations made by the authors have arisen from the literature and the DID data. They do not necessarily represent the official position of UK Sport and should not be interpreted as such.

Competing interests: None.

\section{REFERENCES}

1. Lippi G, Franchini M, Guidi GC. Doping in competition or doping in sport? Br Med Bull 2008;86:95-107.

2. Trout GJ, Kazlauskas R. Sports drug testing - an analyst's perspective. Chem Soc Rev 2004;33:1-13.

3. Kayser B, Smith ACT. Globalisation of anti-doping: the reverse side of the medal. $\mathrm{Br}$ Med J 2008;337:a584.

4. Rivier L. Is there a place for hair analysis in doping controls? Forensic Sci Int 2000;107:309-23.

5. Kintz P. Testing for anabolic steroids in hair: a review. Legal Med 2003;5:S29-33.

6. Kintz P. Detection of doping agents in human hair. In: P Kintz, ed. Analytical and practical aspects of drug testing in hair. Taylor \& Francis, 2006:241-54.

7. Gambelunghe $\mathbf{C}$, Sommavilla $\mathrm{M}$, Ferranti $\mathrm{C}$, et al. Analysis of anabolic steroids in hair by GC/MS/MS. Biomed Chromatogr 2007;21:369-75.

8. Guimarães AE, Pacheco MTT, Silveira L Jr, et al. Near infrared raman spectroscopy (NIRS): A technique for doping control. Spectroscopy 2006;20:185-94.

9. Maughan RJ, Depiesse F, Geyer H. The use of dietary supplements by athletes. J Sport Sci 2007;25:S103-13.

10. Ciocca M. Medication and supplement use by athletes. Clin Sports Med 2005;24:719-38.

11. Corrigan B, Kazlauskas R. Medication use in athletes selected for doping control at the Sydney Olympics (2000). Clin J Sport Med 2003;13:33-40.

12. McDowall JA. Supplement use by young athletes. J Sports Sci Med 2007;6:337-42.

13. Petroczi A, Naughton, DP, Mazanov J, et al. Performance enhancement with supplements: incongruence between rationale and practice. J Int Soc Sports Nutr 2007:4:19. 
14. Petroczi A, Naughton DP, Mazanov J, et al. Limited agreement exists between rationale and practice in athletes' supplement use for maintenance of health: a retrospective study. Nutr J 2007;6:34.

15. Erdman KA, Fung TS, Reimer RA. Influence of performance level on dietary supplementation in elite Canadian athletes. Med Sci Sports Exerc 2006;38:349-56.

16. Alaranta A, Alaranta $\mathrm{H}$, Heliovaara $\mathrm{M}$, et al. Ample use of physician-prescribed medications in Finnish elite athletes. Int J Sports Med 2006;27:919-25.

17. Alaranta A, Alaranta H, Helenius I. Use of prescription drugs in athletes. Sports Med 2008;38:449-63.

18. Huang SH, Johnson K, Pipe AL. The use of dietary supplements and medications by Canadian athletes at the Atlanta and Sydney Olympic Games. Clin J Sport Med 2006;16:27-33.

19. Taioli E. Use of permitted drugs in Italian professional soccer players. Br J Sports Med 2007:41:439-41.

20. Warner DC, Schnepf G, Barrett MS, et al. Prevalence, attitudes and behaviours related to the use of nonsteroidal anti-inflammatory drugs (NSAIDs) in student athletes. J Adolesc Health 2002;30:150-3.

21. Van Thuyne W, Delbeke FT. Declared use of medication in sports. Clin J Sport Med 2008;18:143-7.

22. Anshel MH. Substance use: Chemical roulette in sport. In: Murphy S, ed. The sport psychology handbook. Champaign, IL: Human Kinetics, 2005:255-77.

23. Lippi G, Franchini M, Guidi GC. Non-steroidal anti-inflammatory drugs in athletes. Br J Sports Med 2006; 40:661-3.
24. Berglund B, Sundgot-Borgen J. Sports medicine update. Scand J Med Sci Sports 2001;11:369-71.

25. UK Sport. http://www.100percentme.co.uk/home.php (accessed 15 Jan 2008).

26. British National Formulary (http://www.bnf.org.uk/bnf) (accessed 8 Feb 2008).

27. Chemist and Druggist (http://www.chemistanddruggist.co.uk/1) (accessed 8 Feb 2008)

28. Monthly Index of Medical Specialties (http://www.healthcarerepublic.com/mims) (accessed 8 Feb 2008).

29. Drug Information Database (http://www.didglobal.com) (accessed 12 Feb 2008)

30. WADA Prohibited List 2006 (http://www.wada-ama.org/rtecontent/document/ 2006 LIST.pdf) (accessed 10 Jan 2008).

31. WADA Prohibited List 2007 (http://www.wada-ama.org/rtecontent/document/ 2007 List En.pdf) (accessed 10 Jan 2008).

32. Holzer K, Brukner P. Screening of athletes for exercise-induced bronchoconstriction Clin J Sport Med 2004;14:134-8.

33. Alaranta A, Alaranta $\mathrm{H}$, Palmu $\mathrm{P}$, et al. Asthma medication in Finnish Olympic athletes: no sign of overuse of inhaled $\beta_{2}$-agonist. Med Sci Sports Exerc 2004;36:919-24.

34. Van Thuyne W, Van Eenoo P, Delbeke FT. Nutritional supplements: prevalence of use and contamination with doping agents. Nutr Res Rev 2006;19:147-58.

35. Somerville SJ, Lewis M. Accidental breaches of the doping regulations in sport: is there a need to improve the education of sportspeople? Br J Sports Med 2005:39:512-16. 